City University of New York (CUNY) CUNY Academic Works

1990

\title{
A developmental perspective and antisocial behavior: Cognitive functioning
}

Irvin Sam Schonfeld

cUNY Graduate Center

\section{How does access to this work benefit you? Let us know!}

More information about this work at: https://academicworks.cuny.edu/cc_pubs/281

Discover additional works at: https://academicworks.cuny.edu

This work is made publicly available by the City University of New York (CUNY).

Contact: AcademicWorks@cuny.edu 
logenetic differences (Kendler \& Kendler, 1975). Employing a Darwinian framework is a useful strategy for all researchers, including those who investigate conceptual behavior.

The above is not offered as a recipe to guarantee success. It is based on the premise that psychology must make a determined effort to elevate its research goals, not simply to complete interesting studies but to conduct experiments that are specifically designed to get at crucial theoretical issues even at the risk of embarrassing one's own position. Only such a strategy can yield reliable knowledge.

\section{REFERENCES}

D'Amato, M. R., \& Van Sant, P. (1988). The person concept in monkeys (Cebus apella). Journal of Experimental Psychology: Animal Behavioral Processes, 14, 43-55.

Herrnstein, R. J. (1979). Acquisition, generalization, and discrimination reversal of a natural concept. Journal of Experimental Psychology: Animal Behavior Processes, 5, 116129.

Kendler, H. H. (1987). Historical foundations of modern psychology. Monterey, CA: Brooks/ Cole.

Kendler, H. H., \& Kendler, T. S. (1975). From discrimination learning to cognitive development: A neobehaviorist odyssey. In W. K. Estes (Ed.), Handbook of learning and cog. nitive processes (Vol. 1, pp. 191-248). Hillsdale, NJ: Erlbaum.

Kendler, H. H., Kendler, T. S., \& Marken, R. S. (1969). Developmental analysis of reversal and half-reversal shifts. Developmental Psychology, 1, 318-326.

Medin, D. L. (1989). Concepts and conceptual structure. American Psychologist, 44, 14691481.

Wasserman, E. A., Kiedinger, R. E., \& Bhatt, R. S. (1988). Conceptual behavior in pigeons: Categories, subcategories, and pseudocategories. Journal of Experimental Psychology: Animal Behavioral Processes, 14, 235-246.

\section{Disunity Versus Diversity \\ Josef Brožek \\ Lehigh University}

I profited from reading Wayne Viney's (October 1989) interesting article on "William James and the Unity-Disunity Problem in Psychology," but must take exception to his claim that "The disunity of contemporary psychology is amply documented by the 47 divisions of the American Psychological Association (APA) and literally hundreds of specialty areas" (p. 1264).

The use of the term disunity, I believe, is unfortunate. Disunity is used where diversity would have been the ap- propriate term. Unfortunately, a great deal more is involved than a bit of terminological quibbling: Although the growth in the number of the APA divisions is a manifestation of a healthy and continuing differentiation of the interests of the association's membership, the formation of a competing American Psychological Society reflects an unhealthy disunity.

The issue of an effective model of psychology is not new. An interesting early model was proposed by the German psychologist Hans Henning (1932) in his slim but meaty volume entitled Contemporary Psychology. In contrast to the link-chain pattern of the divisional structure of the APA, Henning offered a circular model, with general experimental psychology at the center and the individual branches of applied psychology located at the periphery and forming a loose circle.

Henning's scientific profile was multiphasic. He has been best known for his volume on smell (1924), characterized in the subtitle as a "handbook for the fields of psychology, physiology, zoology, botany, chemistry, physics, neurology, ethnology, linguistics, literature, esthetics, and the history of culture [Kulturgeschichte]." At the Technical University of Danzig (now Gdansk, Poland), Henning served as professor of philosophy, psychology, and education.

In 1933, the year that Hitler's National Socialists came to power, Henning was relieved of his duties on racial (rassenpolitisch) grounds and his Contemporary Psychology essentially disappeared from the market. In view of the rarity as well as the inherent significance of the volume, it is useful to reproduce the list of the fields and topics of applied psychology that were considered in the book and supplemented by separate lists of selected references:

Ethnological psychology (Völkerspychologie)

Psychology of law

Psychology of language

Economic and industrial psychology (Psychotechnik)

Ethical behavior (Moralpsychologie)

Psychology of art

Psychology of religion

Special states of consciousness

Parapsychology

Psychopathology

Psychoanalysis

Environmental psychology (Geopsychologie)

Quantitative psychology (Mathematische Psychologie)

Differential psychology

Typological psychology (Individualpsychologie) Group psychology (Massenpsychologie)

Social psychology

Psychology of [higher] culture (Kulturpsychologie)
Psychology of values

Medical psychology

Animal psychology

Child psychology

Educational psychology

Developmental psychology

Psychology of philosophy and philosophy of psychology (Erkenntniskritik)

In examining this list the reader should keep in mind three points:

1. General experimental psychology is the center of Henning's organizational model of psychology.

2. The number of the specific topics with which applied psychology may be concerned was viewed by Henning as vast (unübersehbar).

3. The center and the periphery are constituent parts of the whole. Together they constitute the whole of scientific psychology.

To bring the model up to date, one would need to review some of the terminology, add additional fields and topics, and place at the center of the system not the traditional general experimental psychology but basic psychology, including the history of psychology, psychology's general theory, and its methodological principles (cf. Arnau \& Carpintero, 1989).

\section{REFERENCES}

Arnau, J., \& Carpintero, H. (Eds.). (1989). Historia, teoria y método [History, theories, and methods]. Madrid, Spain: Editorial Alhambra.

Henning, H. (1924). Der Geruch [The smell]. Leipzig, Germany: Barth.

Henning, H. (1932). Psychologie der Gegenwart [Contemporary psychology]. Leipzig, Germany: Kröner.

Viney, W. (1989). The cyclops and the twelveeyed toad: William James and the unity-disunity problem in psychology. American Psychologist, 44, 1261-1265.

\section{A Developmental Perspective and Antisocial Behavior: Cognitive Functioning}

\author{
Irvin Sam Schonfeld \\ City College of New York
}

In the special issue on children (American Psychologist, February 1989), Patterson, DeBaryshe, and Ramsey made a significant contribution in reviewing developmental factors bearing on antisocial conduct. They summarized very important research findings on the adverse effects of coercive parent-child interactions. Later in the article they advanced the view that although academic failure covaries with 
antisocial conduct, academic failure is more likely to be a result of antisocial conduct than antisocial conduct is to be a result of academic failure. An important factor that is related to both school failure and antisocial conduct, however, was not sufficiently discussed, namely cognitive functioning.

Wilson and Herrnstein (1985) suggested that deficiencies in cognitive functioning exert more direct effects on criminal behavior than does response to school failure. A considerable body of research documents the relation between various measures of cognitive functioning and conduct difficulties, whether defined within the context of delinquency (e.g., Short \& Strodtbeck, 1965; Wolfgang, Figlio, \& Sellin, 1972) or the psychiatric nomenclature (e.g., Berger, Yule, \& Rutter, 1975; Schonfeld, Shaffer, O'Connor, \& Portnoy, 1988). Patterns of findings involving conventional IQ tests indicate that the locus of the intellectual differences between antisocial and non-antisocial youth is in verbal ability (Wilson \& Herrnstein, 1985). Schonfeld et al. (1988) found that intellectual differences between youths with and without conduct disorders, although consistent with past findings on differences in verbal ability, might more narrowly be seen as reflecting differences in acculturational learning.

A number of other findings are consistent with the acculturational learning view. These findings underline differences between antisocial and non-antisocial youth in social cognitive competence (Dodge, 1986; Freedman, Rosenthal, Donahoe, Schlundt, \& McFall, 1978). Differences in cognitive functioning between antisocial and non-antisocial youth are likely to emerge out of a variety of acculturational contexts. These contexts include, but are not limited to, family environments. Kazdin (1987) observed that parental rearing practices that are related to children's antisocial conduct are also related to "maladaptive cognitive processes" in children. Parental rearing practices characterized by harsh punishment and coercive exchanges may thus promote antisocial conduct in a number of ways. Such rearing practices directly teach aggressive forms of behavior (Patterson et al., 1989). These family practices are also likely to foster cognitive behaviors in the child that bear on his or her decision to engage in antisocial conduct.

\section{REFERENCES}

Berger, M., Yule, W., \& Rutter, M. (1975). Attainment and adjustment in two geographical areas: II. The prevalence of specific reading retardation. British Journal of Psychiatry, 126, 510-519.

Dodge, K. A. (1986). A social information processing model of social competence in children. In M. Perlmutter (Ed.), Minnesota Symposium on Child Psychology (Vol. 18, pp. 77-125). Hillsdale, NJ: Erlbaum.

Freedman, B. J., Rosenthal, L., Donahoe, C. P., Jr., Schlundt, D. G., \& McFall, R. M. (1978). A social-behavioral analysis of skill deficits in delinquent and non-delinquent adolescent boys. Journal of Consulting and Clinical Psychology, 46, 1448-1462.

Kazdin, A. E. (1987). Treatment of antisocial behavior in children: Current status and future directions. Psychological Bulletin, 102, 187-203.

Patterson, G. R., DeBaryshe, B. D., \& Ramsey, E. (1989). A developmental perspective on antisocial behavior. American Psychologist, 44, 329-335.

Schonfeld, I. S., Shaffer, D., O'Connor, P., \& Portnoy, S. (1988). Conduct disorder and cognitive functioning: Testing three causal hypotheses. Child Development, 59, $993-$ 1007.

Short, J. F., Jr., \& Strodtbeck, F. L. (1965). Group processes and gang delinquency. Chicago: University of Chicago Press.

Wilson, J. Q., \& Herrnstein, R. J. (1985). Crime and human nature. New York: Simon \& Shuster.

Wolfgang, M., Figlio, R. F., \& Sellin, T. (1972). Delinquency in a birth cohort. Chicago: University of Chicago Press.

\section{Some Comments About Cognitions as Causal Variables}

\section{G. R. Patterson \\ Oregon Social Learning Center Eugene, $O R$}

Patterson, DeBaryshe, and Ramsey (February 1989) reviewed some of the empirical findings that showed a significant covariation between measures of achievement and antisocial behavior. A case was made for the view that achievement failures were the result of antisocial behavior.

Schonfeld's comment (in this issue) suggests that deficiencies in cognitive functioning correlate with both antisocial behavior and achievement deficits. He goes on to say that cognitive behaviors may play an important role in determining antisocial behaviors in several different ways. In a recent publication Schonfeld made a case for cognitive deficits as a causal variable (Schonfeld, Shaffer, O'Connor, \& Portnoy, 1988).

In his critique, Schonfeld first directs our attention to verbal IQ as a measure of cognitive competence, then cites a web of correlational findings showing that anti- social individuals generally score lower on verbal measures of IQ. There are two problems with this position. Studies reviewed by Wilson and Herrnstein (1985) involving several thousand male and female youthful and adult offenders consistently showed that the deficit hypothesis applied only to verbal measures of $\mathrm{IQ}$, and not to performance measures. Why should this be? If criminality is caused by a cognitive deficit, one would think it would reflect a general deficit rather than a specific one. Wilson and Herrnstein and Schonfeld have little to say about this. I maintain that the antisocial child's essential noncompliance and coercive style make it difficult to teach him or her academic subjects. There is no great intuitive leap involved in hypothesizing that the same behaviors also interfere with the child's ability to acquire the cultural skills reflected in Verbal IQ scores (Patterson, Reid, \& Dishion, in press). It is not that the delinquent youth isn't smart enough, it is just that she or he hasn't learned very much.

The second problem is a more serious one. Schonfeld goes on to cite his own longitudinal study as evidence for the causal effect of cognitive deficits on antisocial behavior (Schonfeld et al., 1988). In that study, a small, highly selected sample of black males was tested at age 7 and again at age 17. The subjects were assessed for aggressivity and given IQ tests at both the initial and the follow-up probes. It is apparent upon examination of the correlations in Table 4 of Schonfeld et al. that early measures of aggressivity contributed little to later measures of intelligence. On the other hand, early measures of IQ seemed to contribute something to later measures of conduct disorder, even after the initial level of aggressivity was partialed out.

On both counts, the findings seem to support Schonfeld's position. The problem lies in the assessment of aggressivity at age seven. The measure they used was a composite of three ratings made by the psychologists who gave the IQ tests. On the face of it, this seems to be a weak measure of aggression. In fact, the correlation of -.16 between the measure of aggression for seven-year-olds and IQ offers little support for Schonfeld's own cognitive deficit hypothesis.

A more adequately designed longitudinal study of the cognitive deficit hypothesis has been carried out by Huesmann, Eron, and Yarmel (1987). They obtained measures of aggression, intelligence, and achievement for a sample of 600 subjects initially assessed at age eight and then reassessed 22 years later. They 